\title{
INDUSTRIAL HEALTH RESEARCH
}

\author{
THE WORK OF THE INDUSTRIAL HEALTH RESEARCH BOARD, 1918-44
}

BY

\author{
R. S. F. SCHILLING *
}

London

\section{INTRODUCTION}

In the very early part of the nineteenth century when excessively long hours of work were regarded as one of the indispensable conditions of making profits, Robert Owen, a cotton manufacturer, showed that he could make his factory pay by reducing hours. And he could still afford to pay better wages and spend considerable sums on improvements and amenities for his work-people. But it was not until 1892 that the first controlled experiment on the relation between hours and output was conducted by Messrs. Mather and Platt. Mather (1894) showed that the reduction in weekly hours from 53 to 48 caused an increase in production and a decrease in lost time. As in the case of Owen's experience, Mather's experiment did not lead to any general adoption by industry of similar methods, or to any organized scientific study of the subject either by the Government or private firms.

At the beginning of the last war, demands for strenuous and long-sustained industrial effort by workers emphasized the country's ignorance of the effects of hours and conditions of work on health, energy and output. In 1915 the combination of this ignorance and the urgent need to make good a shortage of munitions forced the Government to appoint the Health of Munition Workers Committee, under the chairmanship of Sir George Newman, with terms of reference as follows: 'To consider and advise on questions of industrial
fatigue, hours of labour, and other matters affecting
the personal health and physical efficiency of workers
in munitions factories and workshops.'

These investigations, which were necessarily limited to the making of munitions, produced results which have not lost their value but have certainly been lost sight of with the passage of time. To take one instance, it was shown that in certain processes long hours may be both harmful and uneconomical.

It is, perhaps, worth recording that the final report of this Committee was addressed to the

* Appointed Secretary of the Industrial Health Research Board in July 1942, in succession to Sir David Munro.

L
Right Hon. Winston S. Churchill, who at that time (1918) was Minister of Munitions. The Committee concluded that it was necessary to make arrangements without delay for a national scheme of industrial medical research, and to accord fuller recognition to the importance of industrial hygiene.

Shortly after the dissolution of the Health of Munition Workers' Committee in 1917, the Medical Research Committee (now Medical Research Council) and the Department of Scientific and Industrial Research, with the encouragement of the Home Office, appointed in July, 1918, the Industrial Fatigue Research Board with Sir Charles Sherrington as Chairman and Mr. D. R. Wilson as Secretary. The Board, which embraced all classes of industrial work within its scope, had the following terms of reference:

- To consider and investigate the relations of the hours of labour and of other conditions of employment, including methods of work, to the production of fatigue, having regard both to industrial efficiency and to the preservation of health among workers.'

As a first step the Board took over researches then in progress from the health and welfare section of the Ministry of Munitions. These included a study of the effect of different systems of employment on output in shell-making, and an inquiry into the incidence of multiple accidents. In addition it was decided to start investigations in the iron and steel, cotton, silk, laundry, and boot and shoe industries. The Board appointed for each industry a committee which included panel members representing employers and workers.

Just over two years later, because unemployment and short-time employment had become prevalent, the Treasury gave provisional notice to the Medical Research Council that the continuation of the Board could not be contemplated, and that steps should be taken to transfer any important work to industrial or voluntary associations. The Medical Research Council made strong representations to the Treasury against the abrupt termination of work without inquiry into its value to industry. The Treasury eventually agreed to the continuance of the Board on condition that the Council accepted 45 
full administrative and scientific responsibility. This action not only avoided the sacrifice of valuable work in hand, but allowed new researches to be started. Nevertheless the preoccupations of the Government and of employers' and workmen's organizations, with the urgent economic problems of the post-war period, prevented the Board from developing in the manner anticipated at the time when it was first formed.

Researches which were not invalidated by the variable conditions of work, such as short and irregular hours, were continued. Eventually the direct problem of fatigue became less important as hours of work were reduced and as the enormous expansion of repetitive work made demands more on temperament than on muscular strength. This led to the investigation of boredom in relation to incentives and uniformity and variety of work. The field for research was also widened to include studies of effects on the worker of environmental factors closely related to health, for example atmospheric conditions, lighting and noise.

It was felt that the possession of a title expressing what the Board aimed at eliminating instead of what they wished to promote was a disadvantage. So in 1928 , the word ' health' was substituted for 'fatigue,' and the Board became the Industrial Health Research Board. In 1930 Mr. D. R. Wilson (later Sir Duncan Wilson and Chief Inspector of Factories) returned to the Home Office as Deputy Chief Inspector of Factories, and Sir David Munro succeeded him as Secretary of the Board.

\section{BeTweEN Two WARS}

From the time when it was first formed until the outbreak of the present war, the Board published more than 80 reports. These give a detailed story of pioneer work which could have done much to improve working conditions in factories and mines had the results been more widely applied, particularly in the smaller industrial organizations. The result of one piece of research which has been universally applied is worth recording. The present 'Music while you work' programmes of the British Broadcasting Corporation are the direct outcome of studies by three of the Board's investigators (Wyatt, Langdon and Stock, 1937).

\section{Hours of Work}

Early investigations showed that the longer hours worked in the last war, originally introduced to increase production, actually reduced the rate of working so much that in spite of the longer working hours the gross output declined. As this has been stated in general terms so often but is still not acted on, it is perhaps as well to quote just one of the results (Health of Munition Workers Committee Interim Report, 1917).

'In the operation of turning aluminium fuze bodies the output of a hundred women was recorded. The results were as follows:-
100 WOMEN TURNING FUZE BODIES

\begin{tabular}{c|c|c|c}
\hline Period & $\begin{array}{c}\text { Actual } \\
\text { hours of } \\
\text { work per } \\
\text { week } \\
\text { (average) }\end{array}$ & $\begin{array}{c}\text { Relative } \\
\text { output per } \\
\text { working } \\
\text { hour }\end{array}$ & $\begin{array}{c}\text { Total out- } \\
\text { put (hours } \\
\text { of work } \\
\text { relative } \\
\text { output) }\end{array}$ \\
\hline Nov. 14 to Dec. 29 & $68 \cdot 2$ & 100 & 6820 \\
Feb. 27 to Apl. 16 & $59 \cdot 7$ & 123 & 7213 \\
\hline
\end{tabular}

Reductions in hours were first made on January 30th, and once the effect of shorter hours of labour had become established total output was increased by 8 per cent. although the weekly hours of labour were reduced by $8 \frac{1}{2}$.'

After the evacuation of Dunkirk by the British Expeditionary Force in June, 1940, the demands made on the workers for a bigger output were cheerfully accepted. The long hours which followed were probably necessary, but the period for which they were allowed to continue might have been shortened had reference been made to the experience of the last war.

The importance of breaking up spells of work by means of suitable rest pauses was shown by Vernon in the last war (Health of Munition Workers' Committee, Interim Report, 1917). Later work by Wyatt and Fraser (1925) and Vernon, Bedford and Warner (1927) has illustrated the value of systematic rests, especially in light repetitive work. The results strongly suggest that in many industrial processes the introduction of rests of 5-10 minutes in the middle of the working spell is not only appreciated by the workers but may also be followed by an increase in output of the order of 5-10 per cent. in spite of the shortening of the working time.

The Factories Act, 1937, gives statutory recognition of the value of rest pauses. Under the Act, the working spell is normally limited to $4 \frac{1}{2}$ hours for women and young persons, but it may be increased to 5 hours where a rest pause of at least 10 minutes is allowed in the course of the spell. It is true to state, however, that the optimum relation between rest and activity during working hours in many different kinds of work has not yet been precisely determined.

\section{Environmental Conditions}

It is not always easy. to persuade industry to reduce hours of work or to introduce rest pauses. Apparently some industrialists still believe that the relation between output and working hours is a linear one, i.e. that if one man fills 60 shells in one hour, he will therefore fill $60 \times 12$ in 12 hours. Workers will, in some cases, oppose reductions in working hours because of the resultant decrease in wages-particularly where hourly rates of pay are low. But there should be few insuperable obstacles in the way of improving environmental conditions, except, of course, for shortage of skilled labour and materials in war-time.

There are many examples to be taken from the 
Board's eighty reports which show the ill-effects on health and efficiency of bad lighting, poor ventilation and inadequate heating of workrooms.

Lighting and Vision. The system of localized general lighting used in weaving sheds and other industries where the lamps are mounted just above the loom or working bench can provide uniform illumination over the working area-and darkness overhead - that unhappy partnership of glare and gloom. Weston (1922) showed that in the case of linen weavers, output achieved in normal daylight was substantially higher than that in artificial light. $\mathrm{He}$ also showed that it was uneconomical to delay the use of artificial light until natural illumination reached the 'grumble point.'

Other work by the same investigator demonstrated the value of spectacles for relieving eyestrain and improving industrial efficiency in very fine processes. They are no substitutes for good lighting, but they help the young worker who has normal vision as well as the middle-aged worker (Weston and Adams, 1927, 1928, 1929).

Heating and Ventilation. Atmospheric conditions have considerable effect on efficiency and in many industries the adverse effects of high temperatures have been shown. In the tinplate industry, Vernon (1919) found that without artificial ventilation the output of the metal-rolling teams was 12 per cent. less in the summer months than in winter; but when they had good ventilation from fans revolving overhead their summer output was only 3 per cent. less than in winter.

The effects of atmospheric conditions on health and well-being were studied in a variety of industries. Vernon, Bedford and Warner (1928 and 1931) in separate investigations analysed the sickness records of over 33,000 miners. They found that a rise of $10^{\circ} \mathrm{F}$. to $13^{\circ} \mathrm{F}$. in the dry bulb temperature was associated with an increase of 63-74 per cent. in the sickness rate of miners. They attributed the increased sickness to the men getting chilled before they were able to change their damp clothes at home, for miners who were provided with changing-rooms and baths at the pithead lost less time from sickness than those for whom pithead baths were not available.

Accident liability is increased by exposure to unduly high or low temperatures. Osborne and Vernon (1922) found that munition workers had the lowest number of accidents at an air temperature of $67^{\circ} \mathrm{F}$. The accident rate rose at the lower and higher temperatures. At $52^{\circ} \mathrm{F}$. it was 35 per cent., and at $77^{\circ} \mathrm{F} .23$ per cent. higher than at $67^{\circ} \mathrm{F}$. Vernon, Bedford and Warner (1928) also showed that a much greater number of accidents occurred in deep and hot mines than in shallower and cooler ones.

The industrial medical officer should be constantly concerned with methods of ventilating and heating workrooms. He should know how to measure warmth and air movement, and also the requirements for comfort in different types of work. The work done by the Board on these and allied subjects was fully described by Bedford (1944) in the first issue of this journal.

\section{Accident Proneness}

The medical officer in industry deals with accidents largely from the point of view of providing first-aid treatment for major injuries and continuous treatment in the case of minor injuries. Lately, a few industries have made a forward step in assisting injured workmen to regain full function after injury by providing rehabilitation shops and special centres. All these are important aspects of the industrial medical officer's work, particularly in the heavy trades where the severity and frequency rates of accidents are high. But doctors in industry have not paid sufficient attention to the prevention of accidents. Admittedly the law requires that dangerous machines shall be guarded, but as the Chief Inspector of Factories said in his Annual Report for 1918: 'However well machinery may be guarded, we cannot look for more than a 10 per cent. reduction in the accident rate by the provision of safeguards alone.' It was recognized then as it is now that if every machine is made as far as possible foolproof, there will still be many accidents. The studies of Greenwood and Woods (1919), Newbold (1926), and Farmer, Chambers and Kirk $(1926,1929,1933)$ have established the fact that, with equal exposure to risk, roughly three-quarters of recorded accidents happen to one-quarter of the people exposed. This is true for accidents, in the factory, on the road and in the home.

In practically all factory ambulance rooms detailed records are kept of all minor injuries. How often are they used to detect the accident liability of those employed on various jobs and in different departments, or the accident proneness of individual workers?

\section{Industrial Sickness}

For several years the Board's investigators accumulated and analysed sickness records from a few firms. The absence rates showed a very wide range of variation due partly to dissimilar methods of book-keeping and partly to different conditions of work (May Smith, Leiper and Greenwood, 1936). In other fields, research showed that telegraphists' cramp, formerly thought to be a disease of the central nervous system, was a psychoneurotic manifestation (May Smith, Culpin and Farmer, 1927).

Of the several statistical inquiries made, the most recent was an investigation into the sickness experience of London Transport workers (Bradford Hill, 1937). This work, which was done at the request of the Transport and General Workers' Union, whose Secretary was Mr. Ernest Bevin, at that time a member of the Board, showed that bus conductors and drivers had an excess of gastric illness over tramway conductors and drivers. As a result, conferences were held by the Ministry of Labour in order to inquire further into this health problem and its relation to conditions of employment. In 
a published report of the proceedings (Min. of Labour, H.M.S.O., 1939) it was stated that nervous strain and irregularity of meals were considered to be prominent factors in causing gastric disease. Methods of reducing the strain were suggested.

\section{Vocational Psychology}

Vocational psychology is a subject with which many industrial medical officers are not well acquainted, although it has been effectively applied to industry by the National Institute of Industrial Psychology. It includes vocational selectionwhich aims at finding the right person for the job, and vocational guidance-which attempts to discover the right job for the person.

The main task in vocational psychology is to devise tests which measure intelligence and special abilities, such as mechanical aptitude, and to determine the significance of these in the performance of various tasks. The Board's investigators and others have demonstrated that such methods supply only part of the information required for fitting the square pegs into the square holes. Intelligence tests and sensori-motor tests have been shown to have a predictive value for skilled occupations. Where the predictive value of these tests was compared with the results of entrance examinations in 1130 aircraft apprentices, performance in the psychological tests was more closely related to subsequent proficiency than performance in the entrance examination (Farmer and Chambers, 1929).

Contrary to the belief of many, the use of psychological tests limits the role of personal prejudice and tends to decrease the importance of the part played by academic education in allocating men and women to skilled jobs. Nevertheless their value depends on how they are applied to industry. If used for allocation rather than for rejection of the less fit and less intelligent workers, their scope will be enormous. But it is to be hoped that future work in vocational psychology will be aimed at detecting the capacity of children at an early age so that they can be guided towards careers offering them the best opportunity of success rather than selecting them for jobs-often blind alley jobs-in the interest of the employers' output.

Time and Motion Study

In this branch of their work the Board's investigators had the advantage of being independent of the industries concerned, and were therefore able to direct their attention primarily to the task of lessening the physiological cost of work and not of increasing output and lowering costs of production by forcing the pace for the worker. The value to the worker of a well-directed training scheme in methods of work is well illustrated by Farmer's work (1921) on movement study in metal polishing. He showed that, as a result of instruction, twelve girls roughing spoons were able to reduce the number of strokes per spoon from an average of 119 to an average of 83 , and the average time was reduced from 126 minutes to 89 per three dozen spoons. And if the average earnings of these girls for the three weeks preceding training were taken as 100 , then for each of the three weeks following training they were 127,126 and $136 \frac{1}{2}$ respectively.

Another example of the good effects from the worker's point of view resulting from a study made by the laundry trade may be quoted. Efficient methods of feeding calenders for ironing sheets were demonstrated by films to a group of workers whose own methods of work produced results poor in quality at the cost of sore and bleeding fingers. This instruction led to a very welcome sense of relief among the workers; they were less tired and their fingers ceased to be sore. Incidentally both quality of work and output-estimated at a 10 per cent. increase-were improved (Maule, 1937).

\section{Industrial Solvents}

The Committee on the Toxicity of Industrial Organic Solvents was formed in 1935 as the result of the increasing use by industry of volatile organic solvents. As a first step, a full bibliography of relevant literature was prepared by Ethel Browning (1937). The investigations into the toxic effects of the chlorinated group of solvents which were started at the Chemical Defence Research Station at Porton had to be abandoned at the outbreak of war.

\section{Other Work}

This brief survey by no means tells the whole story of the work done between the two wars. Other pioneer researches were made into problems such as noise and its effect on efficiency, comfortable height of working benches, suitable design of machinery and optimum loads for different classes of worker, and the incidence of psychoneurotic symptoms in various industrial groups and their relation to sickness efficiency and social adaptability.

\section{Since THE OUTBREAK OF WAR}

In the early days of the war health problems associated with excessive hours of work, drafting of new labour into war industries, and toxicological problems which follow in the wake of the manufacture of new weapons and munitions, had not become acute. At this time the Board thought it desirable to remind industry of the lessons to be learnt from previous researches, in order that as the demands on our productive power grew ever more urgent the results of those researches could be applied and a repetition of the errors of 1914-18 avoided. So there was published (I.H.R.B., 1940) the first of a series of emergency reports, which gave a résumé of past work in terms as simple and nontechnical as the subject-matter permitted. In the introduction to this report, industry was invited to consult the Board about new problems. The response was not overwhelming and for the time being the Board's investigators gave up much of their time to carrying out research and giving advice on non-industrial problems of national importance, such as the ventilation of air-raid shelters and military control posts and the clothing of military 
personnel. Much was and is still being done to impart knowledge previously gained by lecturing to industrial medical officers, nurses, welfare supervisors, students in social science, as well as Royal Air Force and Army personnel who are being trained for selection work. Partly as a result of work done by the Board's investigators, the Army Council have adopted selection tests for recruits, and these are now being used on a wide scale.

Quite suddenly the 'bore war' ended, and Britain's small expeditionary force had lost practically all its equipment in France. The longexpected demands fell on industry, and as a consequence hours of work in some cases reached high levels. The effects of these longer hours were revealed by investigations (I.H.R.B., 1942a) into the relation between hours of work and lost time and labour wastage, which had been started in war factories at the outbreak of war. It was shown that lost time due to sickness, injury and absence without permission, was usually low when the weekly hours of work were less than 60 per week but increased as the hours increased up to 75 . High praise was rightly paid by the investigators to the time-keeping of the factory workers, when it was remembered that many of them lived far from the factories and had to put up with air-raids and inadequate transport arrangements. In conclusion, the findings of this investigation showed that the weekly periods of work were much too long and substantial reductions were recommended.

Accidents in industry were increasing, and it was thought advisable to publish a short report on the personal factors which needed to be considered in the prevention of accidents (I.H.R.B., 1942b).

\section{Reconstitution of the Board}

In July, 1942, the Medical Research Council reconstituted the Industrial Health Research Board under the chairmanship of Earl De La Warr. It now has 13 members, comprising an employer, a trade unionist, professors of medicine, psychology and physiology, the Senior Medical Inspector of Factories, the Deputy Chief Medical Officer, Department of Health for Scotland, an industrial medical officer, a statistician, and other members of the medical profession. This Board has been given the following terms of reference :

' To advise and assist the Medical Research Council in promoting scientific investigations into problems of health among workers, including occupational and environmental factors in the causation of ill-health and disease, and the relation of methods and conditions of work to the functions and efficiency of body and mind; and in making known such results of these researches as are capable of useful application to practical needs.'

The changed terms of reference officially brought problems of industrial disease within the ambit of the Board. This is not to say that industrial diseases had been entirely neglected in the past. The Board had previously been associated with two committees appointed by the Council to advise them on the promotion and direction of research into industrial pulmonary diseases and the injurious effects of industrial solvents. The Committee on Industrial Pulmonary Disease has sponsored valuable researches, the most important of which have been those concerned with respiratory dust disease (byssinosis) suffered by cotton operatives (Prausnitz, 1936), and with chronic pulmonary disease in South Wales coalminers (Hart, Aslett, et al., 1942; Bedford and Warner, et al., 1943). The work by Prausnitz showed that the only way of preventing byssinosis was to remove the finest dust, which the ventilating and exhaust appliances in use at that time were incapable of doing.

\section{Pneumokoniosis}

Research in the South Wales coalmines established the occurrence among coalminers of a lung condition due to dust which did not fall within the definition of 'silicosis' as used for compensation purposes. This lung condition has been termed pneumokoniosis of coalminers. In its early stages it shows on the radiograph as reticulation, and later there develop the familiar nodular and conglomerate shadows of well established dust disease in miners. Further, there is found in necropsy material a change in the lungs which Belt and Ferris (1942) called dustreticulation (a chance similarity in name to the radiographic appearance). It was also proved that coal trimmers (i.e. coal-boat loaders) working at the docks in South Wales could suffer from pneumokoniosis. The physical studies associated with this work were undertaken by two of the Board's investigators (Bedford and Warner, 1943).

This investigation led to important changes in the Workmen's Compensation Act, which now provides for the payment of compensation to all workmen in the coalmining industry who contract pneumokoniosis as the result of their employment in or about the mines.

Another consequence has been the renewed interest in the use of water for the prevention of pneumokoniosis by suppression of dust at the coal face. One of the Inspectors of Mines (Jenkins, 1943) introduced the novel method of infusing the coal face with water through bore holes before working the coal. The results have been so promising that an order (S. R. \& O., 1943, No. 1696) has recently been made empowering the Chief Inspector of Mines to direct coalmining undertakings in South Wales to use this or other methods for suppressing dust below ground.

\section{Clinical Research and Occupational Disease}

As time went on it became obvious that there was need for more and more clinical research into occupational diseases and other disorders of a more general kind, although they have always been kept in check in factories by the constant supervision of the Factory Inspectorate. As a first step, the Medical Research Council appointed in February, 1942, as Director of Research in Industrial Medicine, Professor A. W. M. Ellis, who later became Regius Professor of Medicine in Oxford. 
The next step was to establish in May, 1943, a Department for Research in Industrial Medicine at the London Hospital in charge of Dr. Donald Hunter, physician to the Hospital. Thus industrial medicine was rightly brought into close contact with clinical medicine in a big teaching hospital.

\section{Industrial psychology}

A further development is the recent establishment by the Medical Research Council of a unit for research in applied psychology at Cambridge, in charge of Dr. K. J. W. Craik, which will undertake investigations, many of them within the field of the Board.

\section{Present Work of the Board}

Sickness Absence. Lack of data giving the incidence of illness among industrial workers has for years past hampered investigations into the disablement believed to be caused by harmful processes. Without such data the collective health of various groups of workers, and indeed the health of the individual, cannot be assessed. In 1942, as a result of the demand and the urgent need for a practical method of recording sickness absence, the Board set up a committee to consider this subject. This task, which is now nearing completion, has been a difficult one. The subject is both complex and controversial. Some firms have used their own methods of recording for years, and because these methods were evolved separately in each organization, they are unlikely to have essential points in common. Others have never measured sickness absence. When industry realizes that the value of such records lies in their uniformity so that sickness rates for parts of an organization, and for different organizations engaged on the same type of work, can be statistically comparable, many of the difficulties in sickness recording will disappear.

The Board's investigators have made various studies of absence from work in Government and private industries. Some of the reports have not been published for security reasons; but all have shown the extreme variability of the amount of absence of which sickness was the most important single cause. In one investigation which covered 52 factories, the rates varied from 5 to 17 per cent. for men and 9 to 29 per cent. for women. The reasons for this variability were many; but in general absence was related to length and distribution of the working week, transport arrangements, supplies of materials and the attitude of the management towards workers. Where these factors were favourable to the worker, absence from all causes was less.

Methods of payment are also reflected in the worker's attitude to his work. A short investigation in one factory (Davis, 1944) showed that gastric disorders and discontentment with work were more frequent among women paid by the individual bonus method than in those paid on a group bonus system. The desire for some measure of security and for communal effort and reward was made manifest in this factory by a spontaneous and unauthorized sharing of wages.

A short study of the absenteeism among women in two factories (Wyatt, Marriott and Hughes, 1943) showed that contrary to general belief few women habitually lost one or more shifts each week, but a large majority were absent for varying lengths of time at irregular intervals. This suggests the need for a study of the personal causes of absenteeism. Further investigations into the amount, distribution and causes of sickness absence among women, which it is hoped to publish at a later date, have just been completed.

Hours of Work and Output. As previously mentioned, the urgent need for maximum output during the last war first brought the Board into being. And since then the Board's investigators have used variations in output as a criterion of efficiency and as a means by which to judge the optimum length of the working week and conditions of work. In a recent investigation, stable operations were selected for assessing the effect of a reduction in hours of work on output in several munition factories. The most striking feature of the output records obtained was the variability which was caused by $(a)$ change in the design of product, (b) mechanical difficulties and machine breakdowns, (c) variations in the quantity and quality of the material used, (d) progressive improvements in the methods and conditions of work, (e) changes in the type and layout of machines, ( $f$ ) dissatisfaction with the method and rate of payment, and ( $g$ ) occasional friction between management and workers (Wyatt, et al. 1944).

In three groups which were fairly free from disturbing influences, the period after the reduction in hours, varying between 3.3 and 11.5 per cent., showed an increase in hourly output of 3.3 to 6.3 per cent. And the shorter working week was appreciated by the workers. This study illustrated the difficulty of trying to determine the relation between hours of work and output under war-time conditions.

Rotation of Night Shifts. The Board has had inquiries as to whether day and night shifts should be rotated weekly, fortnightly or monthly, or longer. Investigators in the last war gave evidence in favour of the weekly change, but present-day opinion is inclined to favour a longer interval between changes. There is obviously need for further research work in this field for which it is hoped that the Board will be able to obtain the necessary facilities. Here again output is a valuable criterion, and if it is to be used, the many other factors which affect it must as far as possible be eliminated.

Environmental Conditions. A great deal of unpublished work has been done on the ventilation and atmospheric pollution in filling factories and its relation to industrial sickness. New methods of sampling for airborne T.N.T. and other explosives have been used.

Much of the field work on lighting problems has been advisory, as the immediate need is to apply the results of previous researches. A report cover- 
ing the work already done on lighting and the conclusions reached from experience gained during the war is being prepared.

Accidents. Researches are being undertaken in coalmines and factories on the incidence of accidents in relation to occupation, environment, the length and arrangement of hours of work and also training. The object of this work, which will include further studies on accident proneness, is to gain knowledge which can lead to a reduction in the rate of industrial accidents, already much too high.

Vocational Methods. Work now in progress consists mainly of introducing intelligence tests and tests of specific aptitudes into engineering factories as an aid to the selection and allocation of new workers. The aims are twofold: (1) to establish on a firmer basis the validity of vocational tests, both general and specific, and (2) to bring about an improvement in efficiency measurable in terms of increased production, as well as a decrease in transfers, dismissals, and personal friction. Most of the tests used have been designed by the Board's investigators.

Neurosis among Industrial Workers. The objects of this investigation are to find out the proportion of people among groups of industrial workers suffering from neurotic illness and the severity of such illness, and to see if there is any evidence as to its cause. It is too early to give results, but it can be said that the findings in one organization show that neurotic illnesses are responsible for a substantial proportion of lost time in industry. Naturally where, as in the case of this investigation, a psychiatrist makes the assessment on the results of a 30-minute interview and data obtained from a social worker, the incidence will be higher than that indicated by an analysis of causes of sickness absence using the panel doctor's certificate as a criterion.

Industrial Diseases. In the new Department for Research in Industrial Medicine at the London Hospital investigations have already been started on a number of problems, including the effects of exposure to duralumin dust and to dust arising from sugar-cane crushing (bagassosis); on the health hazards in foundries; on those associated with the use of compressed air in vibrating tools; and on the effect of exposure of workers to solvents used in the manufacture of aircraft.

Work undertaken by the Medical Research Council, with the collaboration of the Board and the Factory Department of the Ministry of Labour, includes investigations into the toxicity of the vapour of methyl alcohol, the hazards of welding, and dust in flax factories. There are others which cannot be mentioned here for security reasons.

Publications. In the past, the Board's reports have been published as scientific records of the results of research. These will always be necessary; but there is a need for publications written in nontechnical language which can be readily understood by busy directors, works managers, workers' repre- sentatives and the workers themselves. A wider knowledge by all concerned of the results of research can lead to a better understanding of the action needed to improve conditions of factory life. With this view in mind, the Board started a new series of pamphlets. Two reports entitled 'Heating and Ventilation: Lighting and Seeing' (I.H.R.B., 1943) and 'Absence from Work: Prevention of Fatigue' (I.H.R.B., 1944) have already been published in this series. Their popularity, both at home and abroad, has proved their need. It is therefore proposed that in future the results of important new research shall be published both in a detailed scientific report as well as in a short, non-technical form.

\section{The Future of Industrial Health RESEARCH}

In war time there is surely a need for research, particularly short-term investigations designed to produce quick results, which, if applied, will assist production by increasing the health and efficiency of workers.

But what about after the war? Will there still be the same need for research? The post-war reorganization of industry and demobilization will certainly demand the placement of both fit and disabled into jobs for which they are physically and psychologically suited. When this is done there will still be other problems only too obvious to the research worker. Industry includes a wide variety of different processes in diverse fields such as the factory, mine, warehouse, ship, railroad and office. In the factory, in particular, some of the minimum requirements for keeping workers healthy are laid down in the Factories Act, 1937. Although the principles outlined in this Act and elsewhere may have a general application to industries other than factories, more attention will have to be given to health problems which exist in almost unexplored fields-particularly shipping and other forms of transport. New problems not yet anticipated will arise in many processes since changes in methods of production are continually taking place.

A few possible subjects for future research are given below:

\section{Heating and Ventilation}

Methods of cooling buildings in hot weather.

The optimum method of using overhead unit heaters in factories, from the point of view of workers' comfort.

Comfort in relation to thermal environment.

Investigations already done could be extended to cover higher temperatures and higher humidities.

Physiological effects of work at high temperatures.

\section{Atmospheric Pollution}

A study of comparative efficiencies of dust-sampling instruments.

Continuation of investigations into atmospheric pollution by dusts in coalmines and factories.

\section{Lighting and Vision}

Methods of improving lighting in coalmines.

Better methods of lighting offices and places of employment other than factories. 
Exploration of means of gauging sufficient and suitable lighting.

Lighting requirements for the partially sighted.

Effects of conditions of lighting on the rate of acquiring visual skills.

Job Analysis and Methods of Work

Physical requirements for various occupations, with particular reference to the type of jobs which can be suitably undertaken by the disabled and adolescent worker.

Design of machinery in the interests of the comfort and efficiency of the worker.

A study of various methods of work to prevent unnecessary strains and risks.

\section{Industrial Psychology}

Investigations into the validity of existing methods of assessment of qualities required for positions of authority (e.g. foremanship) and the possibility of developing objective methods.

Individual and group influences on efficiency and satisfaction with work.

A comparative study of different systems of payment and their relation to strain, satisfaction and efficiency.

Industrial Sickness

An analysis of morbidity rates in various industries and industrial regions. (Such an analysis should in itself provide problems for research).

Practically all the above subjects are related to the general health of workers. The promotion of general health in industry is a much bigger issue than the prevention of specific industrial disease which accounts for but a fraction of the sickness and disability suffered by the working population. Nevertheless industrial diseases do exist, and in aiming at their prevention there are now many opportunities for further research, and there will be more in the future as new processes with toxicological hazards come into being.

But the contribution which research into all problems affecting the well-being of workers can make towards the achievement of maximum health depends not only on the inspiration of the research worker but also on whether or not the results of his researches are applied. And for a wider application of existing and future knowledge we must look to the efforts of Government departments and industry, which latter includes management, industrial medical officers, and the workers themselves.

\section{Acknowledgments}

My grateful thanks are due to Sir Duncan Wilson, Sir David Munro, and my colleagues of the Industrial Health Research Board and the Medical Research Council for their invaluable help, particularly in the preparation of the sections dealing with the past work of the Board and the future problems of research.

\section{REFERENCES}

Bedford, T., and Warner, C. G., Briscoe, H. V. A., Holt, P. F., and Spoor, N.; Nagelschmidt, G.; Bram- mall, A., and Leach, J. G. C., Hicks, D., and Nagelschmidt, G.; Graham, J. I., and Runnicles, D. F. (1943). Spec. Rep. Ser. Med. Res. Coun., Lond., No. 244.

Bedford, T., (1944). Brit. J. industr. Med., 1, 31.

Belt, T. H., and Ferris, A. A. (1942). Spec. Rep. Ser. Med. Res. Coun., Lond., No. 243.

Browning, Ethel (1937). Industr. Hlth. Res. Bd. Rep., No. 80.

Davis, N. M. (1944). Occup. Psychol., 18, 53.

Factories Act, 1937 (1 Edw. 8 \& 1 Geo. 6, c. 67).

Farmer, E. (1921). Industr. Fatig. Res. Bd. Rep., No. 15.

and Chambers, E. G. (1926). Industr. Fatig. Res. Bd. Rep., No. 38.

(1929). Industr. Hlth. Res. Bd. Rep., No. 55. , and Kirk, F. J. (1933). Industr. Hlth. Res. Bd. Rep., No. 68.

Greenwood, M., and Woods, Hilda M. (1919). Industr. Fatig. Res. Bd. Rep., No. 4.

Hart, P. D'Arcy, Aslett, E. A., Hicks, D., and Yates, R. (1942). Spec. Rep. Ser. Med. Res. Coun., Lond., No. 243.

Health of Munition Workers' Committee (1917). Interim Rep., Cmd. 8511; (1918) Final Rep., Cmd. 9065.

Hill, A. Bradford (1937). Industr. Hlth. Res. Bd. Rep., No. 79.

Industrial Health Research Board (1940). Emergency Rep., No. 1; (1942a) Emergency Rep., No. 2; (1942b) Emergency Rep., No. 3; (1943) Pamphlet No. 1; (1944) Pamphlet No. 2.

Jenkins, P. T. (1943). Proc. S. Wales Inst. Engrs., 59, 306.

Mather, W. (1894). The Forty-Eight Hour Week. Manchester.

Maule, H. G. (1937). J. Instn. Brit. Laundries, 18, 323.

Ministry of Labour (1939). The Health of London Central Busmen. London, H.M.S.O.

Newbold, E. M. (1926). Industr. Fatig. Res. Bd. Rep., No. 34.

Osborne, E. E., and Vernon, H. M. (1922). Industr. Fatig. Res. Bd. Rep., No. 19, Pt. A.

Prausnitz, C. (1936). Spec. Rep. Ser. Med. Res. Coun., Lond., No. 212.

Smith, May, Leiper, Margaret A., and Greenwood, M. (1936). Industr. Hlth. Res. Bd. Rep., No. 75.

- Culpin, M., and Farmer, E. (1927). Industr. Fatig. Res. Bd. Rep., No. 43.

Vernon, H. M. (1919). Industr. Fatig. Res. Bd. Rep., No. 1.

—, Bedford T., and Warner, C. G. (1927). Industr. Fatig. Res. Bd. Rep., No. 41.

- (1928). Industr. Fatig. Res. Bd. Rep., No. 51.

No. $\frac{1}{62}$. (1931). Industr. Hlth. Res. Bd. Rep.,

Weston, H. C. (1922). Industr. Fatig. Res. Bd. Rep., No. 20.

__ and Adams, S. (1927). Industr. Fatig. Res. Bd. Rep., No. 40.

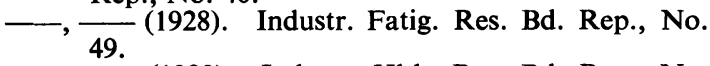
57.

Wyatt, S., and Fraser, J. A. (1925). Industr. Fatig. Res. Bd. Rep., No. 32.

—_ Langdon, J. N., and Stock, F. G. L. (1937). Industr. Hlth. Res. Bd. Rep., No. 77.

Marriott, R., and Hughes, D. E. R. (1943). Industr. Hlth. Res. Bd. Emergency Rep., No. 4.

- - - Dawson, W. M., and Stock, F. G. L. (1944). Industr. Hith. Res. Bd. Emergency Rep., No. 5 . 